\title{
Editorial
}

\section{Las nuevas realidades sociales y ambientales en la transformación del derecho}

La construcción del conocimiento jurídico ha estado en el péndulo de lo práctico o técnico instrumental y lo teórico conceptual, es entre estos dos extremos en los que han aparecido las diferentes concepciones y modos de ser y de hacer del derecho. El derecho como ciencia, como técnica de control social, como instrumento de solución de conflictos, como conjunto de normas que regulan las relaciones de los seres humanos, ha seguido el camino recorrido por las diferentes disciplinas del saber llámense ciencias naturales, ciencias sociales o ciencias del espíritu, en la constitución de su estatuto científico.

En la tensión de explicar o comprender, describir o prescribir, entre la validez y la eficacia, la legitimidad y la legalidad, se ha desarrollado el conocimiento de lo jurídico en el mundo moderno, desde las teorías iuspositivistas, las iusnaturalistas, las realistas, hasta las propuestas contemporáneas como la teoría crítica del derecho y la autopoiesis del derecho.

En su tarea de definir el estatuto científico del derecho, se ha olvidado de las relaciones, de las tramas, de las redes que tiende el derecho en la realidad, en el mundo de la vida- simbólico-biótico. Se ha construido un derecho metafísico, antropocentrista, individualista y purista, que no entiende la realidad cultural y ecosistémica de donde surge. Es por lo anterior que el concepto de derecho moderno está en crisis en tanto no se ha reconocido la red de relaciones, de simbiosis de dependencias e interdependencias, de solidaridades y cooperación que se tejen entre los seres humanos y la naturaleza, no ha reconocido la crisis de la legitimidad por medio de la legalidad, la crisis de su eficacia por sus altos contenidos lógico-formales, crisis del único sujeto jurídico frente a los otras alteridades, la crisis por la falta del dialogo constructivo con otras ciencias, otros saberes y otros sentires.

Los retos que plantea el conocimiento del derecho hoy, son muy diferentes a los planteados en la modernidad y en la construcción de la ciencia jurídica positiva. Nuevos actores, nuevos escenarios, nuevas relaciones políticas y económicas, nuevos problemas planetarios, sociedades más complejas e interdependientes, marcan el rumbo del derecho y de la ciencia jurídica.

Las nuevas realidades y relaciones sujeto-sujeto en la investigación jurídica y socio jurídica

La necesidad creciente de reconocer que las investigaciones jurídicas y sociojuridicas son y forman parte de la reflexión de la investigación social, se debe a las presiones y las condiciones de las sociedades complejas de hoy que exigen una comprensión cada vez más integral de los problemas sociales y de los problemas jurídicos, fenómenos como el deterioro ambiental global, los derechos humanos, la propiedad intelectual, la emigración, entre otros, nos hacen pensar en la exigencia de la construcción de modelos cada vez más complejos para comprender la realidad, que interactúan con nuevos modelos y paradigmas que cruzan las fronteras disciplinares para ubicarse en zonas cada vez más transdisciplinares.

Modelos como la trama de la vida de F. Capra, de la complejidad de E. Morin, ecosistema y cultura A. Angel, entre otros, nos hacen ver que los fenómenos culturales y sociales, entre ellos el derecho, tienen que ser estudiados y comprendidos desde marcos epistemológicos diferentes a los acostumbrados en los estudios jurídicos y sociojurídicos.

La compleja, diversa y rica realidad sociocultural y ecosistema de nuestro país impone al investigador social y por supuesto al investigador de la disciplina jurídica a repensar y a resignificar los objetos y los métodos, pero también las preguntas, es decir, a que de una manera heterodoxa, responsable y rigurosa se pregunte sobre los cómo y los por qué, pero también los quizá, única forma de darle respuestas a las preguntas constantemente formuladas pero aún no respondidas que precisa hoy la sociedad colombiana.

Hoy se hacen insostenibles desde el punto de vista científico y social, posiciones que conciben el derecho como un dado divino, como un epifenómeno, como una construcción lógico formal que responde a mandatos supraculturales, que el derecho es universal, sin injerencia de lo político, de lo ético, lo moral, o lo ecosistémico.

El derecho es una construcción cultural, que forma parte del mundo simbólico en permanente construcción y reconstrucción por las comunidades humanas, el derecho como forma cultural y simbólica sigue el camino de las demás construcciones simbólicas de una cultura, por ejemplo de la manera como una cultura conciba el entorno, lo natural, de esta misma manera serán las formas jurídicas que se produzcan. En culturas en donde las otras alteridades diferentes a las humanas son tomadas como objetos, como cosas, también las formas jurídicas, las instituciones jurídicas las tomarán como objetos. 
Estos son solo algunos de los retos teóricos y metodológicos que se presentan a los investigadores de la disciplina jurídica y que tiene que ver con la formación de nuevos patrones de valoración y de representación simbólica de lo jurídico.

Los cambios están ligados a una revalorización cada vez más positiva de lo jurídico como dimensión de lo social, en donde lo jurídico es otro de los elementos que al lado de lo sociológico, lo filosófico y lo político, involucra el análisis y aplicación y eficacia de las norma en sociedades concretas. Todo esto requiere la conformación de nuevos imaginarios jurídicos construidos desde los ciudadanos, que hacen pensar que la llegada de lo jurídico-legal a la vida social, se convierta en un asunto de renovación y reinvención de nuevas relaciones entre los seres humanos y los demás seres vivos.

De esta forma el derecho y la investigación jurídica serán importantes en la investigación social, en la medida en que las discusiones, las preguntas y las propuestas se inserten en el ámbito local y regional pero pensando en lo global, que se fortalezca el conocimiento jurídico con la participación en grupos interdisciplinarios y que forme parte fundamental en la formación de los nuevos profesionales del derecho, que se pueda insertar dentro del nuevo contexto creado por las urgencias y exigencias de la modernización tecnológica y económica, de los riesgos y amenazas que ha traído la modernidad como manera de comprender el mundo.

La investigación jurídica y sociojurídica pensada desde la investigación social, aporta a la sociedad y al país, bases más sólidas de conocimiento para la formación, aplicación y evaluación legislativa, para la comprensión de lo jurídico en la proyección del desarrollo de lo local y regional, frente a los retos, a las tensiones, a los riesgos y amenazas de la globalización y del desarrollo sostenible. Se requiere entonces de investigaciones que nos indiquen como es la realidad colombiana, frente al comportamiento del derecho y de la justicia y construir referentes que nos permitan comprender la eficacia de uno y otro, conocer situaciones y causas que harían mucho más comprensible la enseñanza del derecho, un positivo desarrollo del mismo y su propia evolución frente a los hechos sociales. En un país donde lo normativo legal es eje estructurador de políticas y programas gubernamentales, se hace necesario el aporte del estudio de lo jurídico en sus dimensiones filosófico, político, económico y social, en su incorporación en la construcción de nuestra realidad.

Encarar críticamente el derecho significa reconocer el papel que juega el derecho como constructor de mundo y como conformador de sentido, como constructor de representaciones y legitimador de instituciones políticas, económicas y sociales. Se requiere incrementar el conocimiento científico de lo jurídico, para dar respuesta no solamente al conflicto sino a los simples requerimientos de la vida cotidiana, para agregar valor, mediante el conocimiento, al mundo de las relaciones sociales y humanas.

El estudio del derecho en la realidad, de su función instrumental y simbólica, se presenta como un gran reto, en tanto los estudios jurídicos en el país se han caracterizado por ser estudios eminentemente teóricos sobre una infinidad de instituciones jurídicas, pero sin ningún referente empírico en la realidad social y cultural. Los bucles, magmas, rizomas y estratos del derecho

El concepto del derecho jerárquico, estático, estatal, piramidal, teológico, clasista, sexista, antropocentrista, monológico, monista y lineal, está mudando, mutando, deconstruyéndose y reconstruyendose a formas jurídicas y de juridicidad complejas, poliformes, circulares, plurales y polisémicas que dan cuenta de un mundo y de una nueva imagen de mundo, diferente a la imagen y semejanza de los postulados modernos y-racionales que construyó la ciencia la ciencia jurídica, es decir la ciencia positiva.

La nueva imagen de mundo jurídico que se construye hoy, es descentrada desde lo teórico, lo epistemológico, lo disciplinar y lo geográfico. Desde lo teórico se hacen deconstrucciones y reconstrucciones que nos demuestran la maleabilidad del objeto de la ciencia jurídica.

La reconstrucción y decostrucción disciplinar del derecho se da en la interrelación y confluencia del derecho con otras ciencias normativas, sociales $y$ naturales que nos muestran la inconsistencia y fragilidad de las teorías jurídicas forjadas a partir de postulados puristas. Las teorías jurídicas contemporáneas y las nuevas emergencias del derecho como los derechos humanos, el derecho ambiental, el derecho de las nuevas tecnologías, son las afloraciones de los rizomas del derecho en movimiento, del derecho material convertido en bucles y en afloraciones del mundo simbólico biótico. .

Los centros de producción y recepción del conocimiento jurídico hoy no san tan identificables claramente, como lo eran en la modernidad. Las instituciones y las formas jurídicas de la globalización emergen no ya de los estados-nación sino de los estados-región, de los organismos internacionales, de las empresas transnacionales, de las organizaciones no gubernamentales trasnacionales y cada vez menos de los parlamentos nacionales. La recepción del derecho y de las teorías en su origen nacional eran resignificadas y rematerializadas en las instancias y por los autores nacionales. Las formas jurídicas de la globalización y su formulación teórica vienen ya empaquetados de tal forma que los parlamentos de los estados-nación recepcionantes no les queda sino la opción de aprobar los tratados ya negociados en instancias cada día 
menos jurídicas y políticas, y si más económicas de las organizaciones mundiales como la ONU, la OMC, el FMI, el BM o el BID, que negocian la libertad de las personas, negocian la naturaleza, negocian la felicidad y el hambre como si fueran mercancías.

El ideal de un derecho universal, monológica, jerárquizado y monista tiene su revés, su bizarro, en una serie de fenómenos jurídicos que aparecen y desaparecen en diferentes tiempos y diferentes espacios, que se mantienen pero se desconocen por el derecho oficial, que se les nombra pero no se les llama, se les reconoce pero no se legitima, se legitima pero no se legaliza, es decir, unas manifestaciones sociales que pueden ser formas jurídicas pero que han tenido la fuerza, no han sido reconocidas por el poder (s) para tener su estatuto jurídico.

Estos fenómenos jurídicos que no sintonizan en la partitura del derecho oficial y del poder, se caracterizan por ser polisémicos y multidiversos, plurales y atonales, es decir, expresiones del mundo de la vida-simbólico-biótico, que contradicen y muchas veces compiten con la versión oficial del derecho.

Los rizomas en el derecho aparecen en la forma de pluralismo jurídico que obliga a formular un concepto pluralista o social del derecho que acepta también la existencia de un derecho no estatal, en contra de la concepción monista o estatista del derecho, que reconoce en los sistemas sociales unas reglas no necesariamente dentro de los circuitos jurídicos estatales. La justicia ambiental es otro rizoma, que emerge acompañado con atractores extraños, que hace bucle con otros de movimientos antiglobalización.

Las jerarquías enmarañadas brotan y contradicen la pretendida jerarquía jurisdiccional que se rompe en nuestro país, cuando por vía de Acción de Tutela y para proteger un derecho fundamental, un juez de la más inferior categoría desconoce una sentencia de la Corte de
Suprema de Justicia, la máxima autoridad jurisdiccional del país; el derecho fundamental protegido por vía de tutela actúa como atractor extraño y rompe esta relación jerárquica de las providencias judiciales.

El derecho hoy debe responder a las nuevas necesidades y nuevas realidades que enfrentan las sociedades contemporáneas, signadas por la crisis de valores, de pensamiento, crisis ambiental o la pudiéramos llamar una crisis civilizatoria o crisis de la cultura. El paradigma del derecho formal decimonónico debe dar paso a los enigmas del mundo de la vida-simbólico-biótica, a la formulación de nuevas relaciones y nuevos imaginarios. El derecho como producto cultural, que se produce en el mundo simbólico de los seres humanos, debe construir nuevos referentes, nuevos símbolos que acerquen más a los seres humanos con su entorno.

El derecho red

Las nuevas propuesta del derecho plantean que las instituciones jurídicas basadas en los postulados modernos de libertad, igualdad y autonomía de la voluntad, se reconstruyan a partir de los postulados de heteronomía, solidaridad, cooperación e interdependencia, en donde no prime lo individual, el sujeto sobre el objeto, sino que lo colectivo, lo de todos, sea el punto de referencia para las nuevas instituciones jurídicas.

Esta es la metáfora del derecho a construir en las sociedades complejas de hoy, es el derecho red en donde los juristas no quieren estar, lejos de la seguridad ii jurídica ii que da un derecho jerárquico, metafísico, uniforme, autónomo, monista, sexista, que trata a lo no humano, a la naturaleza como objeto.

Pensar en un derecho red implica deshacerse de las ataduras epistemológicas, lógico- formales construidas por el derecho racional moderno, detenerse ante el abismo de los enigmas y de las afloraciones de la vida tal como es, no como el derecho se la imagina.

\title{
Javier Gonzaga Valencia Hernández
}

\author{
Profesor Asociado Universidad de Caldas. Abogado. Magíster en \\ Sociología. Magister en Derecho ambiental y de la sostenibilidad. \\ Doctor en Derecho ambiental y de lasostenibilidad
}

